\title{
VELOCITY MEASUREMENTS ON DAUGAARD-JENSEN GLETSCHER, SCORESBY SUND, EAST GREENLAND
}

by

Niels Reeh and Ole B. Olesen

(The Geological Survey of Greenland, Østervoldgade 10, DK-1350 Copenhagen, Denmark)

\section{ABSTRACT}

The surface movement of Daugaard-Jensen Gletscher, East Greenland, a fast-moving outlet glacier from the Greenland ice sheet, was determined by means of theodolite measurements, using intersections from observation stations on bedrock, once or twice a day, during a ten-day period. With a gap of about three weeks, the observation programme was resumed for another three days which allowed "long term" mean velocities to be calculated, as references for a study of velocity fluctuations on time scales in the range 2-10 days. Various methods of analysing non-synchronous theodolite measurements on fast-moving glaciers are discussed, and previously-reported large velocity fluctuations are critically reviewed. It is concluded that, on the time scales studied, velocities in the frontal region of Daugaard-Jensen Gletscher fluctuate by up to $15 \%$. However, on one occasion, a velocity increase of more than $50 \%$ was observed, lasting for about 7.5 hours. This event is inferred to be the result of a sudden increase in the water pressure of the subglacial drainage system, caused by the tapping of an ice-dammed lake behind the glacier front. The more moderate velocity fluctuations are most likely also due to changes of the subglacial hydraulic system.

\section{INTRODUCTION}

In the summers of 1968 and 1972, a glaciological programme was carried out by the authors as part of The Geological Survey of Greenland's mapping project in East Greenland. Preliminary results were presented by Olesen and Reeh (1969) and Henriksen (1973). A detailed analysis of the 1968 observations was given by Olesen and Reeh in an unpublished report. The movement observations on Daugaard-Jensen Gletscher will be analysed in this paper and problems, arising when dealing with non-synchronous theodolite observations on fast-moving glaciers, will be discussed.

Daugaard-Jensen Gletscher $\left(71^{\circ} 55^{\prime} \mathrm{N}, 28^{\circ} 33^{\prime} \mathrm{W}\right)$ is the most productive of the outlet glaciers from the Greenland ice sheet, calving into Scoresby Sund, East Greenland. The glacier terminates at the head of Nordvestf jord, the northernmost branch of the Scoresby Sund fjord system (Fig.1), with a calving front approximately $6 \mathrm{~km}$ wide and $500 \mathrm{~m}$ thick. The thickness was estimated from observations on icebergs overturning after calving and thus exposing the vertical cross-section of the glacier. A thickness of about $500 \mathrm{~m}$ also results, if the central part of the frontal region of the glacier, with a rather constant mean height of about $60 \mathrm{~m}$, is assumed to be afloat. At the front, the velocity of the glacier exceeds $12 \mathrm{~m} / 24 \mathrm{~h}(4 \mathrm{~km} / \mathrm{a})$. The calving flux has been estimated at $10 \mathrm{~km}^{3}$ of ice per year (Olesen and Reeh, 1969), which amounts to $3-4 \%$ of the total calving flux from the Greenland ice sheet and is comparable to that of the major west Greenland outlet glaciers.

\section{THE OBSERVATIONS}

The motion of the glacier was determined by repeated theodolite (Wild T2) intersections, once or twice a day, from observation stations on bedrock to characteristic

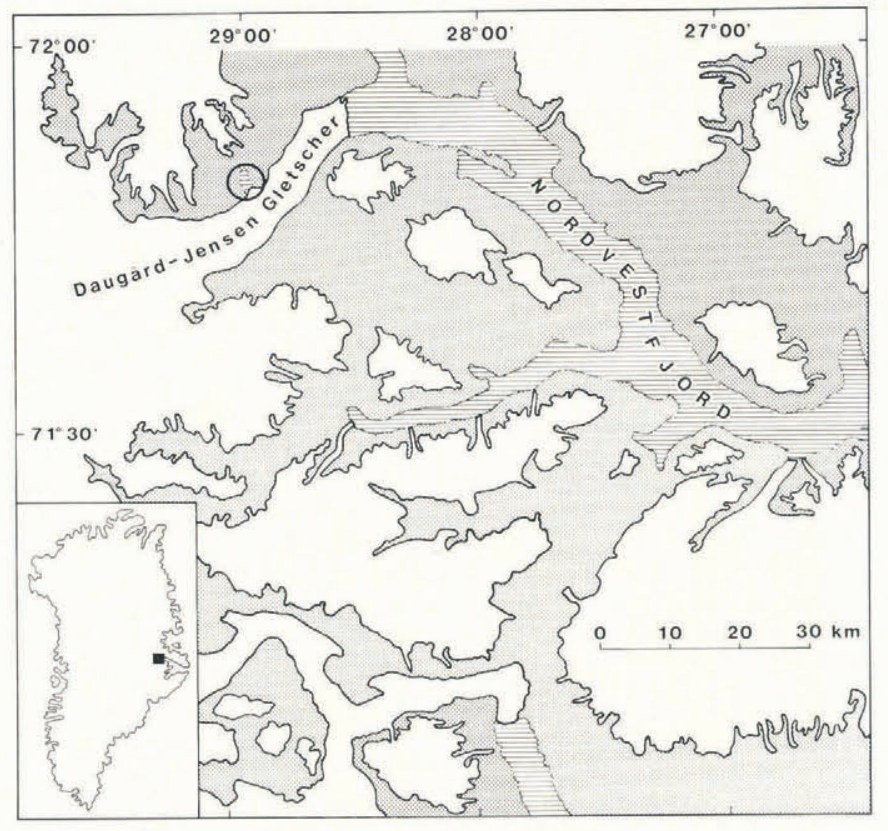

Fig.1. Location map of Daugaard-Jensen Gletscher. Position of ice-dammed lake is indicated by a circle.

features on the glacier surface. During the period of observation, several of these natural target points changed their appearance or even disappeared, due to ablation or collapse. For this reason, the periods of observation for the various points were very different, ranging from less than a day to 32 days. Altogether, 40 points, distributed over the frontal portion of the glacier, were observed, allowing the spatial distribution of the surface velocities to be established (Fig.5). Moreover, some target points survived for a period sufficiently long to permit velocity fluctuations to be studied on time scales ranging from a few days to about one week.

\section{DATA ANALYSIS}

Due to the observation technique applied (nonsynchronous sightings to moving target points from two, fixed, observation stations), the path lines of the target points cannot be calculated directly from the pairs of observations; adjustment of the observation angles is required. A simple method of adjustment is to refer the angles to the same time by linear interpolation between the observed values. The zig-zag paths, shown in Figure 2, represent a map-view of the path lines determined by such adjustments for four selected target points. Each path line may be divided into two sections characterized by large, then small, oscillations, reflecting a change from a $93 \mathrm{~m}$ base line $(6801-6802)$ to a $373 \mathrm{~m}$ base line $(6801-6807)$, at time 7100 minutes. Moreover, the oscillations of the path 

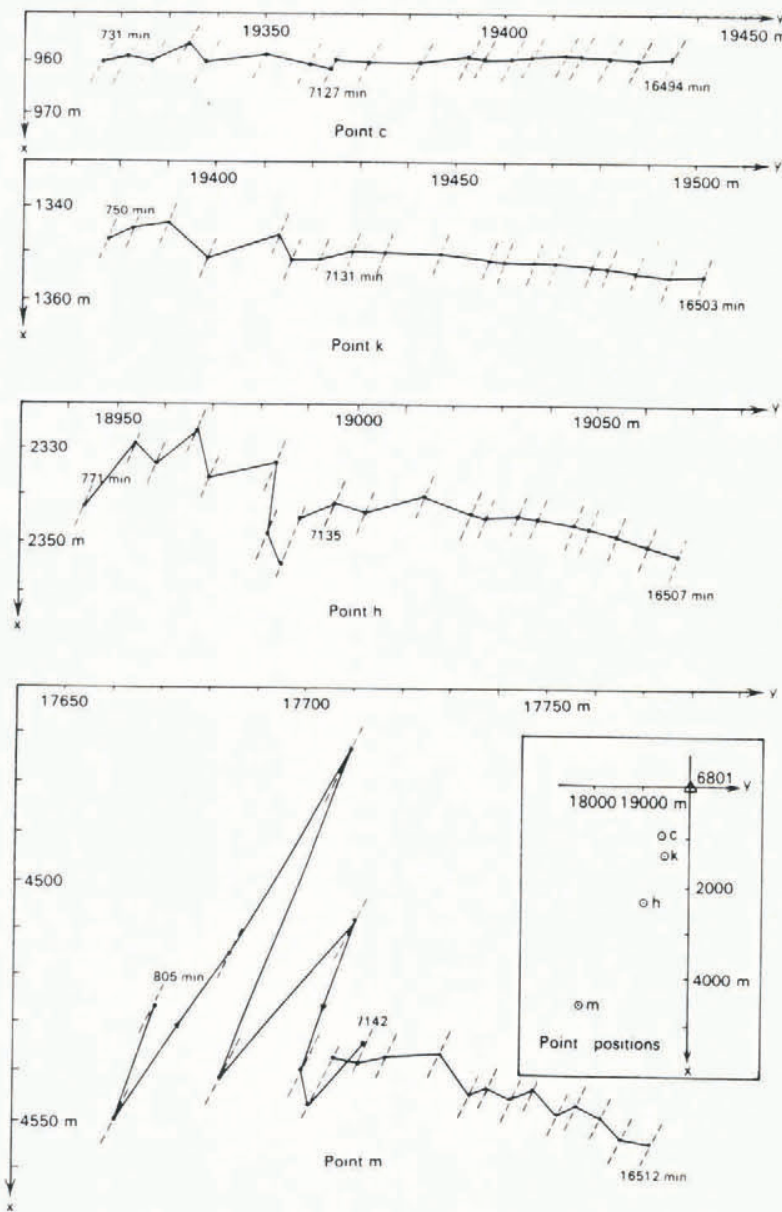

Fig.2. Horizontal projections of the path lines of four target points obtained by the method of linear interpolation of the observation angles. The numbers along the path lines are times in minutes from an arbitrarily chosen origin. Point 6801 is the common end point of the two base lines applied.

lines distant from the base line display larger amplitudes than do those close to the baseline. This strongly supports the assumption that the illustrated zig-zag motions are fictitious and generated merely by an inappropriate adjustment procedure. A simple test will confirm this suspicion.

According to the theory of errors for the method of intersection, the uncertainty of a target point position is accounted for by an error ellipse, which, however, in the actual case of small intersection angles, degenerates into an error line bisecting the intersection angle. The directions (not the magnitudes) of the error lines are indicated in Figure 2 by dashed lines through the inferred point positions. The true positions of the target points are somewhere on these error lines. In Figure 3 , error lines are shown, corresponding to two successive times. Since the movement of the target point $M$ in the intervening interval is small, as compared to the distance from the base line, the error lines are approximately parallel. The common azimuth of the error lines is denoted $\epsilon$, see Figure 3. The positions of the target point, at times $t_{1}$ and $t_{2}$, as obtained by the linear interpolation method, are shown in Figure 3 as $M_{1}$ and $M_{2}$, respectively. Since $M_{1}$ and $M_{2}$ are tied to the error lines, there is a strong correlation between the magnitude and the azimuth, $\alpha_{\mathrm{v}}$, of the line segment, $\mathrm{M}_{1}-\mathrm{M}_{2}$, and therefore also between the derived magnitude, $\mathrm{v}=\left(\mathrm{M}_{2}-\mathrm{M}_{1}\right) /\left(\mathrm{t}_{2}-\mathrm{t}_{1}\right)$, and azimuth, $\alpha_{\mathrm{v}}$, of the velocity vector. From Figure 3 , the following relationship can be deduced

$$
v=v_{0} / \sin \left(\epsilon-\alpha_{v}\right),
$$

where $v_{0}$ is the component of the velocity vector normal to the direction of the error lines.

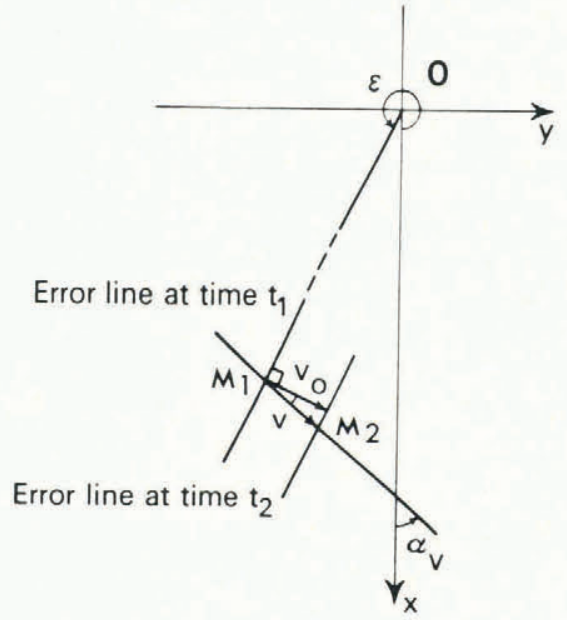

Fig.3. Error lines, corresponding to two successive times of interpolation. $\mathrm{v}$ and $\alpha_{\mathrm{y}}$ are the magnitude and azimuth, respectively, of the inferred movement of a target point, $M$, in the interval, $t_{2}-t_{1} . M-O$ represents the direction to the observation points (the base line).

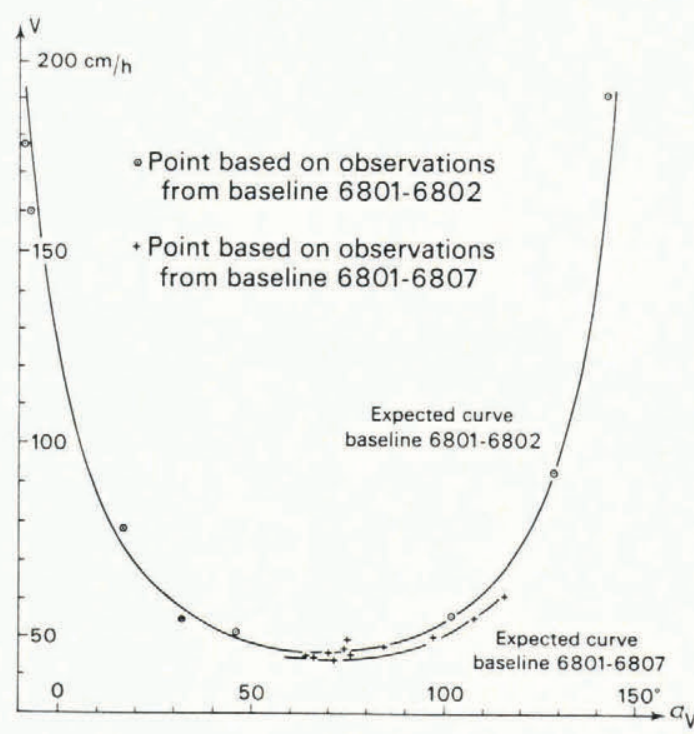

Fig.4. Comparison of the expected relationship (eq(1)) between magnitude, $v$, and azimuth, $\alpha_{v}$, of the velocity vector for target point, $\mathrm{h}$, about $2.5 \mathrm{~km}$ from the base lines, and pairs of values of $v$ and $\alpha_{v}$ obtained for the various intervals by the linear interpolation method. The mean velocity of the point is about $50 \mathrm{~cm} / \mathrm{h}$ in direction $\alpha_{\mathrm{v}}=80^{\circ}$.

In Figure 4 , the curves represent the expected relationship (eq(1)) for target point, $h$, positioned about $2.5 \mathrm{~km}$ from the observation stations. Pairs of values of $v$ and $\alpha_{v}$, obtained for the various intervals between the times of interpolation, are shown by point markings in the figure. The close fit of the points to the curves clearly indicates that the zig-zag paths shown in Figure 2 do not represent the actual motions of the target points and, therefore, that a more elaborate analysis is needed to derive the true glacier motion from the observations. The optimal procedure to apply for such an analysis would be to define the flow field of the glacier by a mathematical expression with a sufficient number of parameters to account for the spatial as well as the temporal variations of the velocity field and estimate these parameters by a least-squares fit, using al observations available. This would lead to a rather comprehensive least-squares calculation. A substantia reduction in the calculations is achieved by modelling the motion of each target point separately, as do Dahl-Jensen and others (1986). 
In this work, an "in between" approach has been used; for each target point, smooth angle variations with time were determined by linear regression smoothing of the observations and a mean motion calculated by means of the smoothed angles. This mean motion, illustrated by the velocity vectors shown in Fig.5, is almost identical to the least-squares solution found by Dahl-Jensen and others

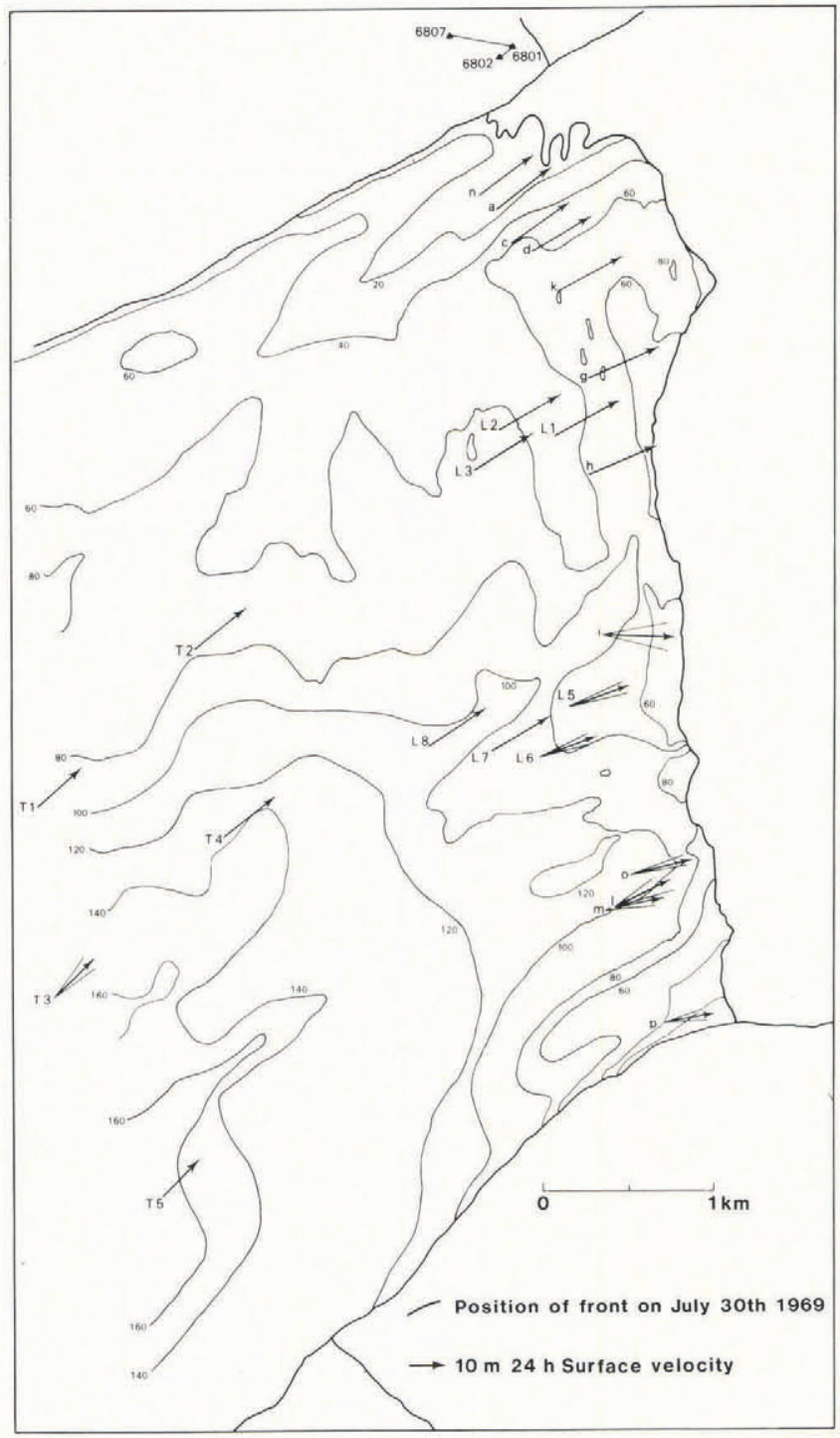

Fig.5. Map of frontal region of Daugaard-Jensen Gletscher. Surface elevations are in metres. Observed velocities are shown by arrows. Thin lines on either side of arrows indicate error limits, where large enough to be shown.

(1986). Next, the deviations of the observed angles from the regression lines (Fig.6) were analysed in terms of fluctuations in the magnitude and the azimuth of the velocity vectors. Thus, it is not assumed, a priori, as do Dahl-Jensen and others (1986), that the target points move along straight lines and that the angle fluctuations are caused by fluctuations solely in the magnitude of the velocity vectors.

The contributions to the angle variations from fluctuations in the magnitude and the azimuth of the velocity vector can be sorted out by a multiple regression analysis, if it is assumed that the respective fluctuations are synchronous, for the observed points. This is indicated by the angle deviation curves shown in Figure 6 for points c, $h$, k, and $m$ (for location: see Figure 5), which are the points with the longest continuous records of observation. The analysis is performed along the following lines:

The motion of a point, M, moving at constant velocity,

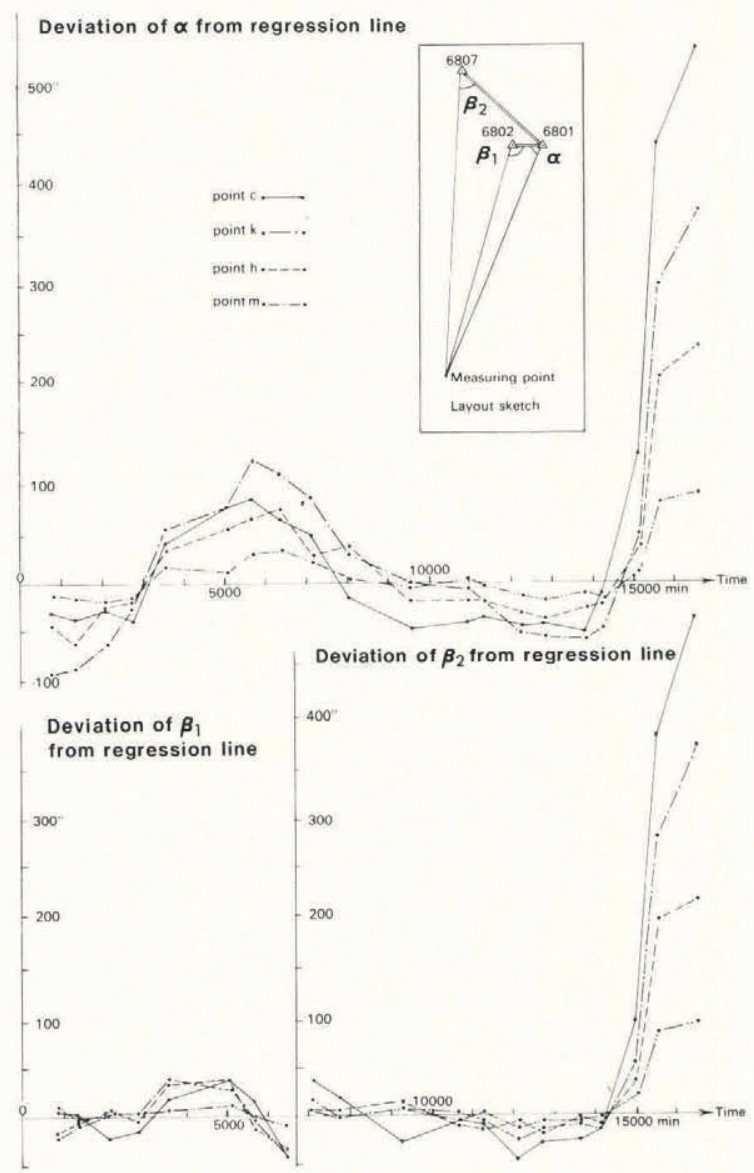

Fig.6. Deviations of observed horizontal angles from linear regression lines for four target points. 6801, 6802, and 6807 are observation stations. Time is in minutes from an arbitrarily chosen origin.

$\mathrm{v}_{0}$, in a fixed direction parallel to the $\mathrm{y}$-axis, is determined by the equations $\mathrm{x}=\mathrm{x}_{0}$ and $\mathrm{y}=\mathrm{y}_{0}+\mathrm{v}_{0} \mathrm{t}$, where $\left(\mathrm{x}_{0}, \mathrm{y}_{0}\right)$ is the position of the point at time $t=0$, see Figure $7 \mathrm{a}$. Denoting the distance, $O M$, at time $t=0$, by $b_{0}$, the increase in azimuth, d $\alpha$, is determined by

$$
\tan (\mathrm{d} \alpha)=\left(\mathrm{v}_{0} \mathrm{t} \cos \alpha_{0} / \mathrm{b}_{0}\right) /\left(1+\mathrm{v}_{0} \mathrm{t} \sin \alpha_{0} / \mathrm{b}_{0}\right) .
$$

Expanding the right hand member of this equation in a series to third order in the small quantity, $v_{0} t / b_{0}$, one obtains

$$
\begin{aligned}
\mathrm{d} \alpha & \sim \mathrm{v}_{0} t \cos \alpha_{0} / b_{0}-\left(v_{0} t / b_{0}\right)^{2} \sin \alpha_{0} \cos \alpha_{0} \\
& +\left(v_{0} t / b_{0}\right)^{3} \cos \alpha_{0}\left(1-x_{1} \cos ^{2} \alpha_{0}\right) .
\end{aligned}
$$

Using values of $v_{0}, b_{0}$, and $\alpha_{0}$, determined by the linear regression analysis mentioned previously, it appears that the third order term is negligible, whereas the first and second order terms are both significant.

Next, consider the case of a point, $\mathrm{M}$, moving along a path line shaped as a small amplitude sine curve (see Fig. $7 \mathrm{~b}$ ), with a velocity, the magnitude of which also varies sinusoidally with time. This motion is approximately described by the equations

$$
\mathrm{x}=\mathrm{x}_{\mathrm{o}}+\mathrm{a}_{\alpha} \mathrm{T} \mathrm{v}_{\mathrm{o}} /(2 \pi) \sin \left(2 \pi \mathrm{t} / \mathrm{T}+\Phi_{\mathrm{v} \alpha}\right)
$$

and $\mathrm{y}=\mathrm{y}_{0}+\mathrm{v}_{0} \mathrm{t}+\mathrm{a}_{\mathrm{v}} \mathrm{Tv}_{0} /(2 \pi) \sin (2 \pi \mathrm{t} / \mathrm{T})$,

where $a_{\alpha}$ and $a_{v}$ are the amplitudes of the fluctuations in azimuth and magnitude of the velocity vector, respectively, and $T$ is the corresponding period. $\Phi_{v \alpha}$ accounts for a possible phase difference between the fluctuations in azimuth and magnitude, respectively. 

written

The angle variation with time for this case may be

$$
\begin{aligned}
& \mathrm{d} \alpha=\mathrm{v}_{0} \mathrm{t} \cos \alpha_{0} / \mathrm{b}_{0}-\left(\mathrm{v}_{0} \mathrm{t} / \mathrm{b}_{0}\right)^{2} \sin \alpha_{0} \cos \alpha_{0} \\
& +\left(\mathrm{v}_{0} \cos \alpha_{0} / \mathrm{b}_{0}\right)\left(\mathrm{a}_{\mathrm{v}} \mathrm{T} /(2 \pi)\right) \sin (2 \pi \mathrm{t} / \mathrm{T}) \\
& -\left(\mathrm{v}_{0} \sin \alpha_{0} / \mathrm{b}_{0}\right)\left(\mathrm{a}_{\alpha} \mathrm{T} /(2 \pi)\right) \sin \left(2 \pi \mathrm{t} / \mathrm{T}+\Phi_{\mathrm{v} \alpha}\right) .
\end{aligned}
$$

Subtracting eq(2) from this equation and taking the variance of the residual, one obtains

$$
\begin{aligned}
& \mathrm{s}(\Delta \alpha)^{2}= \\
& 1 / 2\left(\mathrm{v}_{0} \cos \alpha_{0} / \mathrm{b}_{0}\right)^{2}\left(\mathrm{a}_{\mathrm{v}} \mathrm{T} /(2 \pi)\right)^{2}+\not / 2\left(\mathrm{v}_{0} \sin \alpha_{0} / \mathrm{b}_{0}\right)^{2}\left(\mathrm{a}_{\alpha} \mathrm{T} /(2 \pi)\right)^{2} \\
& \quad(\mathrm{c}) \quad(\mathrm{d}) \\
& +\left(\mathrm{v}_{0} / \mathrm{b}_{0}\right)^{2} \cos \alpha_{0} \sin \alpha_{0} \mathrm{a}_{\mathrm{v}} \mathrm{a}_{\alpha} \mathrm{T}^{2} \rho /(2 \pi)^{2}+\mathrm{s}(\alpha)^{2},
\end{aligned}
$$

where $\rho$ is the correlation between the magnitude and the azimuth of the velocity vector. This demonstrates a division of the total variance, $s(\Delta \alpha)^{2}$, into contributions from fluctuations in (a) magnitude of the velocity vector, (b) azimuth of the velocity vector, (c) combinations of these two, and (d) errors of the angle measurement.

For each target point, the variance, $s(\Delta \alpha)^{2}$, and the quantities, $\left(\mathrm{v}_{\mathrm{o}} \cos \alpha_{\mathrm{o}} / \mathrm{b}_{\mathrm{o}}\right)^{2}, \quad\left(\mathrm{v}_{\mathrm{o}} \sin \alpha_{\mathrm{o}} / \mathrm{b}_{\mathrm{o}}\right)^{2}$, and $\left(\mathrm{v}_{\mathrm{o}} / \mathrm{b}_{\mathrm{o}}\right)^{2}$ $\cos \alpha_{0} \sin \alpha_{0}$, can be calculated, using results from the linear regression analysis. On the assumption that $a_{v} T$ and $a_{\alpha} T$, separately, are the same for all points, estimates of these quantities, as well as of $\rho$ and $s(\alpha)^{2}$, can be found by means of multiple regression analysis. Moreover, the significance of each term can be tested.

\section{RESULTS}

An analysis of the angle deviations, illustrated in Figure 6 (leaving out the large deviations for $t>$ $15000 \mathrm{~min}$ which will be subject to a separate analysis), shows that only the term, $\left(v_{0} \cos \alpha_{0} / b_{0}\right)$, contributes significantly to the variance (level of significance $>99 \%$ ). It is, therefore, concluded that the angle fluctuations are mainly accounted for by fluctuations in the magnitude of the velocities. The regression analysis also provides the following estimates

$$
1 / 2\left(\mathrm{a}_{\mathrm{v}} \mathrm{T} /(2 \pi)\right)^{2}=2.37 \pm 0.14 \mathrm{~h}^{2}
$$

and

$$
\mathrm{s}(\alpha)^{2}=(-9.5 \pm 9.2) \times 10^{-9} .
$$

From Figure 6, the "period" of the fluctuation is estimated to $\mathrm{T} \sim 12000$ minutes $\sim 8$ days. Using this value in eq(3), $\mathrm{a}_{\mathrm{v}}$ is calculated to be 0.07 . Thus, in the 10-day period used in this analysis, velocities in the frontal portion of the glacier display a "long-term" oscillation within the range 9.3 - $10.7 \mathrm{~m} / 24 \mathrm{~h}$, taking the time-averaged velocity in the period to be $10 \mathrm{~m} / 24 \mathrm{~h}$.

Superimposed on this "long-term" fluctuation are fluctuations with shorter periods. For the time interval 9500 - $14000 \mathrm{~min}$, where continuous records of observations are available for 17 target points, a regression analysis results in the following estimates:

$$
\begin{aligned}
& 1 / 2\left(\mathrm{a}_{\mathrm{v}} \mathrm{T} /(2 \pi)\right)^{2}=0.023 \pm 0.006 \mathrm{~h}^{2}, \\
& 1 / 2\left(\mathrm{a}_{\alpha} \mathrm{T} /(2 \pi)\right)^{2}=0.047 \pm 0.015 \mathrm{~h}^{2},
\end{aligned}
$$

$$
s(\alpha)^{2}=(1.0 \pm 0.15) \times 10^{-9},
$$

whereas the mixed term in eq(3) turns out not to contribute significantly to the variance. A "period" of $T=3000$ minutes $\sim 2$ days is inferred for this fluctuation, resulting in $\mathrm{a}_{\mathrm{v}}=0.03, \mathrm{a}_{\alpha}=0.04$, and $\mathrm{s}(\alpha)=3 \times 10^{-5} \sim 6.5^{\prime \prime}$. These numbers indicate fluctuations in the magnitude and azimuth of the velocity vector of $6 \%$ and $4 \%$, respectively, on a time scale of the order of 2 days. The non-explained part a)
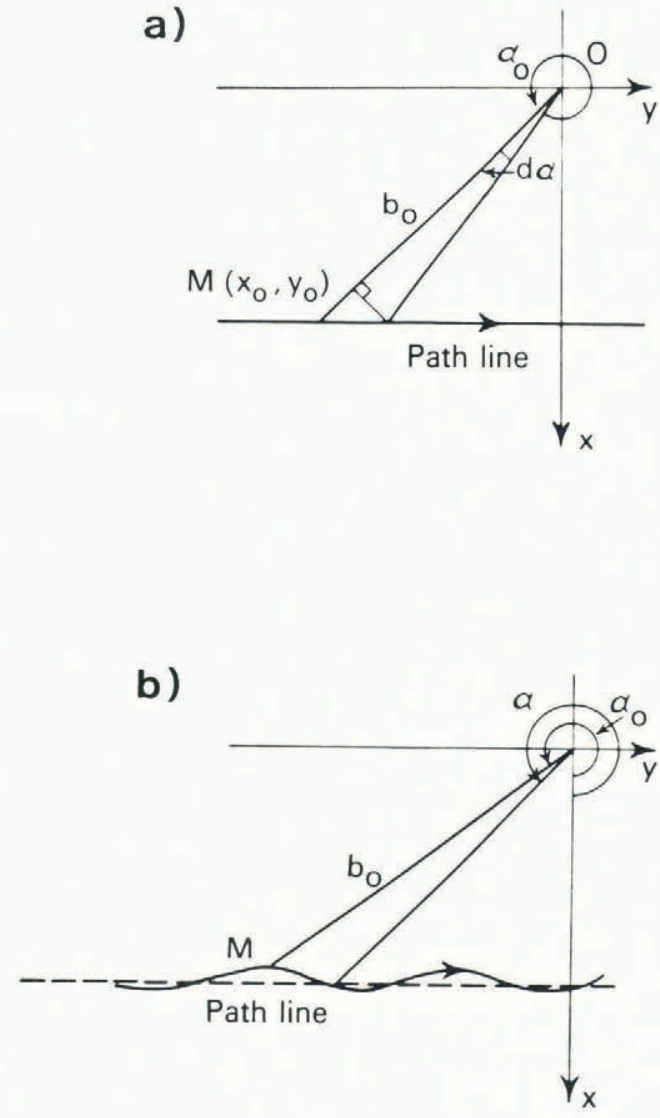

Fig.7. Idealized motions of a target point, M. (a) illustrates motion along a straight path line with constant velocity. (b) illustrates motion along a curved path line with oscillating velocity. Symbols are explained in the text.

of the angle variance, which corresponds to an angle standard error of 6.5", probably represents the error of the sightings, arising from using natural points as targets, from refraction phenomena, and from turning of the theodolite tripod (no measures were taken for protection against solar radiation and winds).

Finally, the dramatic rate of increase of the horizontal angles in the time interval, 15000-15650 min (Figure 6), has been analysed. It appears that the jump-like increase of the angles corresponds to an excess movement, of the order of magnitude of $2 \mathrm{~m}$, mainly in the direction of the mean motion of the glacier. If this excess movement is evenly distributed over the corresponding time interval of about $7.5 \mathrm{~h}$, a velocity increase of approximately $6 \mathrm{~m} / 24 \mathrm{~h}$ results, i.e. a more than $50 \%$ increase, relative to the average.

\section{DISCUSSION AND CONCLUSIONS}

Velocities of Greenland outlet glaciers have been studied for more than a century. Table 1 summarizes the results of studies in which velocity variations were determined by means of theodolite surveys. As appears from the table, velocities are reported to display large fluctuations, deviations from the mean of more than $100 \%$ not being unusual. This is in contrast to the more moderate fluctuations of about $10-15 \%$ found in the present study. (The unusual event of a $50 \%$ velocity increase in a rather short period will be commented on later). In a few cases (Drygalski, 1897; Sorge, 1933; Bauer, 1955 and 1968; Zick, 1972) the method of data reduction has been described and sufficient data have been published to allow an evaluation of the reported velocity fluctuations. In all these cases, it turns out that zig-zag path lines, similar to those presented in Figure 2, have been accepted as actually representing the glacier motion and velocity fluctuations have been derived accordingly.

In the light of the analysis presented in this work, we conclude that the previously-reported, very irregular ("turbulent") motions of Greenland outlet glaciers most likely 
TABLE I. VELOCITY OBSERVATIONS ON GREENLAND OUTLET GLACIERS

\begin{tabular}{|c|c|c|c|c|c|c|c|c|}
\hline Glacier & & Date & $\begin{array}{l}\text { Number } \\
\text { of } \\
\text { points } \\
\text { observed }\end{array}$ & $\begin{array}{l}\text { Interval } \\
\text { between } \\
\text { observations } \\
\text { (days) }\end{array}$ & $\begin{array}{l}\text { Maximum } \\
\text { number } \\
\text { of } \\
\text { observations } \\
\text { of each } \\
\text { point }\end{array}$ & $\begin{array}{l}\text { Range } \\
\text { of mean } \\
\text { velocities } \\
\mathrm{m} / 24 \mathrm{hrs}\end{array}$ & $\begin{array}{l}\text { Range } \\
\text { of reported } \\
\text { velocity } \\
\text { eluctuations } \\
\text { in } \%\end{array}$ & Reference \\
\hline Upernavik Isstrom & August & 1886 & 8 & $0.29-0.94$ & 5 & $1.4-31.2$ & ++ & C.H. Ryder (1889) \\
\hline Upernavik Isstrom & April & 1887 & 11 & $0.94-1.02$ & 5 & $1.3-10.3$ & $8-69$ & C.H. Ryder (1889) \\
\hline Upernavik Isstrom & April & 1931 & 6 & $1-3$ & 14 & $0.8-18.2$ & $13-111$ & W.S. Carlson (1941) \\
\hline Rink Isbræ & July & 1932 & 4 & 1 & 5 & $27.9-35.1$ & $10-27$ & E. Sorge (1933) \\
\hline Store Gletscher & \multicolumn{2}{|c|}{ Aug 1892-July 93} & 85 & $1-67$ & 49 & $0.3-19.6$ & $1-323$ & E. von Drygalski (1897) \\
\hline Eqip sermis & \multicolumn{2}{|c|}{ September 1948} & 12 & $1-3$ & 6 & $1.3-3.8$ & $47-208$ & A. Bauer (1955) \\
\hline Eq1p sermia & June & 1949 & 11 & 1 & 3 & $2 \cdot 8-4 \cdot 3$ & $9-86$ & A. Bauer (1955) \\
\hline Eqip sermia & July & 1959 & 9 & $1-2$ & 4 & $1.1-3.7$ & $14-70$ & A. Bauer (1968) \\
\hline Eq1p sermia & \multicolumn{2}{|c|}{ July-August 1972} & 9 & $1-?$ & 21 & $1.0-4.0$ & $16-100$ & W. Zick (1972) \\
\hline Jakobshavn Isbræ & \multirow{2}{*}{\multicolumn{2}{|c|}{$\begin{array}{l}\text { March-April } 1880 \\
\text { July-August } 1968\end{array}$}} & 5 & $0.42-20.43$ & 10 & $5.2-12.5$ & $8-35$ & R.R.I. Hammer (1883) \\
\hline Daugaard-Jensen & & & 39 & $0.17-21$ & 25 & $7 \cdot 2-11 \cdot 2$ & see & O.B. Olesen \& \\
\hline Gletscher & & & & & & & text & N. Reeh (this work) \\
\hline
\end{tabular}

+ Results too scattered to give comprehensive results

result from an unsatisfactory data analysis and that, even though velocity fluctuations do occur, they are much more moderate than has of ten been reported.

Velocity fluctuations of such magnitude and frequency as those found in this study are most likely to be referred to changes in the subglacial hydraulic system (Iken, 1981; Kamb and others, 1985). Unfortunately, sea-level changes, which constitute the downstream boundary control on the pressure in the subglacial drainage system, were not recorded at the glacier front. Nor has other information been collected about the subglacial drainage system. It is therefore not possible, from this study, to deduce or verify theories relating velocity fluctuations to changes of the subglacial drainage system. However, one event, i.e. the extraordinary velocity increase of more than $50 \%$, observed in the period 12 to 18 hours on August 1 (15 100 - 15500 min on the time scale of Fig.6), can unquestionably be related to a major change of the subglacial hydraulic system. This was caused by drainage of a $3.8 \mathrm{~km}^{2}$, ice-dammed lake, situated at the northern margin of the glacier, at an elevation of $430 \mathrm{~m}$, some $17 \mathrm{~km}$ behind the front, see map in Figure 1. Documentation of this event, in the form of observations of openings in the dense ice cover of the fjord in front of the glacier, upwelling of water from beneath the glacier front, the observation that the glacier-dammed lake had drained on August 6, and an observed relative uplift of the glacier, will be given in a paper in preparation.

The more moderate velocity fluctuations of $10-15 \%$, on time scales in the range $2-10$ days, are probably also to be explained in terms of pressure changes of the subglacial hydraulic system, caused by tides, wind impounding, and perhaps also variable supply of surface melt water to the subglacial drainage system.

Semi-diurnal velocity fluctuations, with amplitudes of $10-15 \%$ of the average related to the semi-diurnal tidal variation, have been recorded in the frontal region of Jakobshavn Isbræ, West Greenland (Echelmeyer personal communication). If observed twice a day, at regular intervals, which was the measuring procedure applied at Daugaard-Jensen Gletscher, such a variation would manifest itself as a fictitious "long-term" velocity fluctuation, with a period of 15-16 days and an amplitude of about $3 \%$ of that of the true semi-diurnal fluctuation, i.e. less than $1 \%$ of the mean velocity. The velocity fluctuations deduced in this study have considerably shorter periods and much larger amplitudes and therefore cannot be explained as such an effect.

\section{ACKNOWLEDGEMENT}

This manuscript is published with the permission of the Director of the Geological Survey of Greenland.

\section{REFERENCES}

Bauer A 1955 Glaciologie. Groenland. Vol 2. Le glacier de l'Eqe. Expéditions Polaires Françaises 44 (6)

Bauer A 1968 Le glacier de l'Eqe (Eqip sermia). Mouvement et variations du front (1959). Meddelelser om Gronland 174(2)

Carlson W S 1941 Report of the northern division of the Fourth University of Michigan Greenland Expedition 1930-31. University of Michigan Studies. Scientific Series 6: $61-156$

Dahl-Jensen D, Steffensen J P, Johnsen S J 1986 Least-squares method used in reduction of data from theodolite measurements on fast moving glaciers. Annals of Glaciology 8: 42-46

Drygalski E von 1897 Grönland-Expedition der Gesellschaft für Erdkunde zu Berlin 1891-1893. 1. Berlin, W H Kühl

Hammer R R I 1893 Undersøgelser ved Jakobshavns Isf jord og nærmeste Omegn i Vinteren 1879-1880. Meddelelser om Gronland 4(1)

Henriksen N 1973 Regional mapping and palaeomagnetic and glaciological investigations in the Scoresby Sund region, central East Greenland. Gronlands Geologiske Undersogelse. Rapport 55: 42-47

Iken A 1981 The effect of the subglacial water pressure on the sliding velocity of a glacier in an idealized numerical model. Journal of Glaciology 27(97): 407-421

Kamb W B and 7 others 1985 Glacier surge mechanism: 1982-1983 surge of Variegated Glacier, Alaska. Science 227(4686): 469-479

Olesen O B, Reeh N 1969 Preliminary report on glacier observations in Nordvestfjord, East Greenland. Gronlands Geologiske Undersogelse. Rapport 21: 41-53

Ryder C H 1889 Undersøgelse af Grønlands Vestkyst fra $72^{\circ}$ til $74^{\circ} \mathrm{N}$. Br. 1886 og 1887 . Meddelelser om Gronland 8(7): $203-270$

Sorge E 1933 Universal - Dr. Fanck Grönland-Expedition 1932. Umiamako und Rink Gletscher. Berlin, Deutsche Universal-Film AG

Zick W 1972 Eisbewegungen am Eqip Sermia und im westlichen Randgebiet des grönländischen Inlandeises (EGIG Arbeitsgebiet). Polarforschung 42(1): 24-30 